\title{
Rapid on-line sampler-injector: a reliable tool for HT-HP sampling and on-line GC analysis
}

\author{
P. Guilbot, A. Valtz, H. Legendre and D. Richon* \\ Laboratoire de Thermodynamique CEREP-TEP, Armines - École des mines, \\ 35, rue Saint Honoré, 77305 Fontainebleau, France
}

\begin{abstract}
Withdrawing of representative and reliable microsamples down to $1 / 100$ th $\mathrm{mg}$ is far from trivial, especially for extreme conditions such as high temperature and high pressure conditions or very corrosive media. The new Rapid On-Line SamplerInjector presented herein was designed and set-up to largely extend sampling capabilities in hazardous media. It is largely used in our laboratory to measure vapour-liquid equilibria. It has a lot of applications, both in production (process control in petroleum, chemical, nuclear plants, etc.) and academic and industrial researches and development (laboratory instruments, pilot plants...).
\end{abstract}

Keywords. Sampler - fluid injector - high pressures - high temperatures - chromatography - on-line analysis

\section{Introduction}

On-line sampling interests both research and process control laboratories.

In the field of process control, Fraser [1] says: "One of the most important, but often poorly designed, facets of an on-line analytical system for gas processing facilities is the sample conditioning system (SCS). The sample delivered to the gas Chromatograph must truly represent the process media if the measurement is to be accurate - or even meaningful." In industry, micro-sampling is generally performed using rotating sampling valves (equipped with external or internal commercial loops), sealing being ensured between a mobile polymer element and a static metallic body. The main problem encountered using polymers is that some of them are dedicated to withstand for high temperatures or high pressures or for corrosive mixtures, but no polymer is able to withstand for a combination of these three problems.

In the past years, a lot of methods have been developed for sampling. They were rather dedicated to research equipments (phase equilibrium studies) and not to the process control. Peter and Eicke [2] carried out analyses on part of the samples taken from a container after expanding. It is important to take a special care to ensure the liquid samples do not undergo any vaporisation and to avoid any condensation of the heavy fractions inside the transfer line. Pawlikowski et al. [3] also used the technique of expanding the samples on-line with the same inconveniences. A valve with a sampling loop was used to send a small quantity of the sample into a gas chromatograph. Valuev et al. [4] developed an instrument somewhat more complex that the preceding ones, using a ball to obstruct the sampling line and letting the sample flow in the hollow axis of a needle that rests against the ball. A considerable dead volume is characteristic for this type of sampling. Jacoby and Tracht [5] have conceived a pressure-resistant removable sampling valve, which can be placed in the sampling line, then removed to carry a sample for injection into chromatograph carrier gas as proposed some years before by Yarborough and Vogel [6]. This type of sampling requires at least one shut-off valve, one or more sampling valves and one valve for pressure drop. This series of valve creates important and complex-shaped dead volumes, which are difficult to purge. For a measurement campaign, several valve assembling and disassembling are required, increasing the risk of non-thermal equilibrium in the whole apparatus and the possibility of leaking. Several authors developed systems allowing to withdraw samples at constant pressure. For example, Ellis et al. [7] recover the vapour and liquid samples in containers initially filled with mercury. The hazards with mercury are non-negligible and the temperature range is rather limited. To take samples as close as possible to the equilibrium cell, Rodgers and Prausnitz [8] have designed a cell with pistons passing through the walls of the cell. These pistons allow to extract small samples (some $\mu \mathrm{l}$ ) and send them directly into a chromatograph carrier gas circuit. Unfortunately, the main problem with this technique is to achieve a reliable sealing between the piston and the wall of the cell. Dorokhov et al. [9] developed a new sampling technique by trapping a small sample between two stems inside the equilibrium cell body. The main drawbacks are: the need of two expansions for each sampling and the presence of non-negligible dead volumes, especially in the carrier gas circuit (heavy components may remain partially inside the channel and may undergo a partial vaporisation). To solve

*Correspondence and reprints.

Received March 9, 2000; revised May 29, 2000; accepted May 30, 2000. 
these problems, Figuière et al. [10] developed another sampling system with valves. The blocking cones of the valve stems are pushed against equilibrium cell seatings by very strong spring washers achieving a perfect sealing. The stems are moved backward by calibrated shocks allowing to withdraw about one $\mu l$ of both liquid and vapour samples. The carrier gas flowing along the channel machined along the valve stem sweeps the samples totally (no dead volume). Samplings are done very quickly (time less than $0.1 \mathrm{~s}$ ) and the sample sizes can be monitored by modifying the aperture shocks. The equilibrium cell of Figuière et al. allows experimental studies up to $673 \mathrm{~K}$ and $40 \mathrm{MPa}$. The sampling systems of Dorokhov et al. [9] and Figuière et al. [10] have one important limitation: the liquid samples must be vaporised at the equilibrium temperature during a relatively short time and at the chromatograph carrier gas pressure. In the case of Figuière et al., the temperature limitation is not so drastic and the equipment can be adapted [11] by simple modifications to equilibrium temperatures lower than the boiling temperature of the heaviest component.

In the scope of its activities, the Laboratoire de Thermodynamique des Équilibres entre Phases (CEREP TEP) of the École Nationale Supérieure des Mines de Paris (France) has developed a pneumatic device based on capillary sampling [12], which works up to $873 \mathrm{~K}$ and up to $100 \mathrm{MPa}$ [13-33]. Its numerous advantages allow it to be positioned not only as a research device but also as a precious tool for industry in process control for the following reasons: it allows withdrawals of very small samples. This is all the more important for various reasons: reliability of samples, analysis of expensive products... Moreover, analysing the withdrawn samples totally and on-line, immediately after sampling (after some tenths of a second), avoids the degradation or the transformation of the sample. In this way, the sample analysed is completely representative of the medium from which it is withdrawn.

\section{Experimental}

\section{Description of the equipment}

The Sampler-Injector shown on photo 1 is a very compact system (see figure 1) without dead volume. It is connected to a cell (for research applications) or a tubing (for process control) through a Monel capillary (C) (internal diameter: $0.1 \mathrm{~mm}$, external diameter: $1 \mathrm{~mm}$ and typical length: $150 \mathrm{~mm}$ ) prolonged by a Titanium micro-needle $(\mathrm{N})$. It is crossed by a gas (entering in I1 and I2) which sweeps the sample to be analysed (at a minimum flow rate of about $15 \mathrm{ml} / \mathrm{min}$ ) to the injector of a gas chromatograph (via outlet $(\mathrm{O})$ ). For practical reasons, the sweeping gas used is the gas chromatograph carrier gas. A typical sweeping flow rate of $15 \mathrm{ml} / \mathrm{min}$ is particularly when using packed or widebore columns but requires some modifications of the downstream analytical circuit if capillary columns are used. In fact, the flow rate has to be reduced just before the capillary column using a split device placed between the injector of the gas chromatograph and the column (see figure 2).

The Sampler-Injector can be operated over some million times without maintenance in most applications. In fact, the lifetime of the system is "infinite" compared to usual

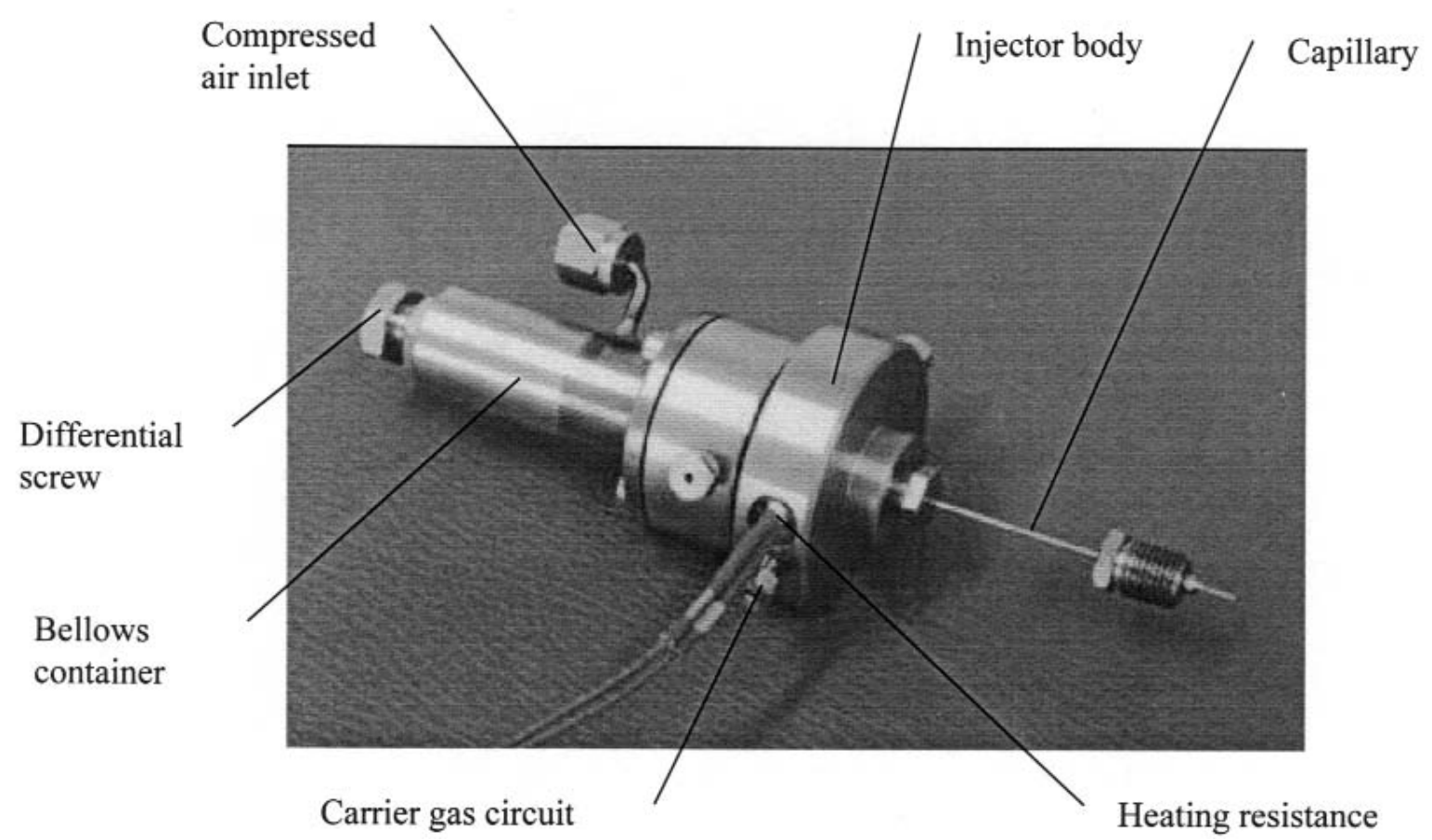

Photo 1. The Sampler-Injector. 


\section{Original articles}

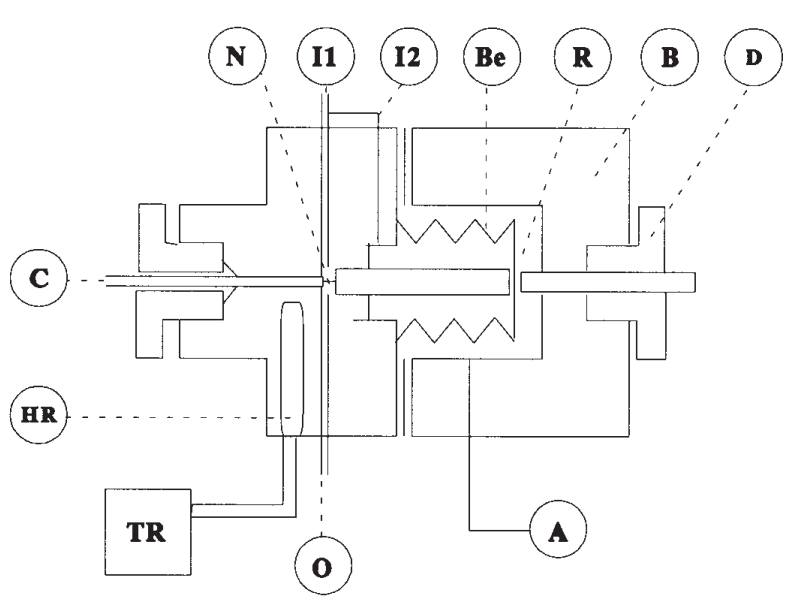

Figure 1. Flow diagram of the Sampler-Injector (in its pneumatic version). A: Air inlet; B: Body; Be: Bellows; C: Capillary; D: Differential screw; HR: Heating resistance; I1, I2: Carrier gas inlet; N: Micro-needle; O: Carrier gas outlet; R: Expansion room; TR: Thermal Regulator.

commercial ones, mainly because all the sealing parts are metallic and do not need lubrication. It can work under very hard conditions: high temperature and high pressure [12], in reactive [32] or corrosive media such as hydrogen sulfide [30-31], ammonia [32], or aqueous amine solutions [33].
The Sampler-Injector allows withdrawing liquid or gas samples. It can be heated, using a heating resistance (HR in figure 1), independently from the vessel or the tubing containing the fluid to be sampled so that a liquid sample can be entirely vaporised quickly in the gas circuit of a gas chromatograph. Consequently, it is especially adapted either to the study of phase equilibria in research laboratories or in industry, for the on-line analyses related to process controls: analyses of liquid or vapour samples directly withdrawn from distillation columns, absorption columns, reactors, storage tanks...

The body and all the elements in contact with the samples are made of stainless steel, titanium or hastelloy.

Generally, the Sampler-Injector is pneumatically controlled for both convenience and safety purposes.

The size of the withdrawn samples can be varied continuously from several hundredths to several mg. This represents a big advantage (especially when VLE, VLLE or LSE, etc., measurements are involved) compared to usual loopsampling valves, which have to be dismounted in order to modify the sample volume. An adjustable volume is particularly useful for various reasons: for checking the validity of a detector calibration, for adjusting the size of chromatographic peak areas to be within the calibration range, and for a rapid purging of the capillary. For process control applications, constant withdrawn volumes are generally required. In this case, the withdrawn volume repeatability during the first thousands times operation (including the

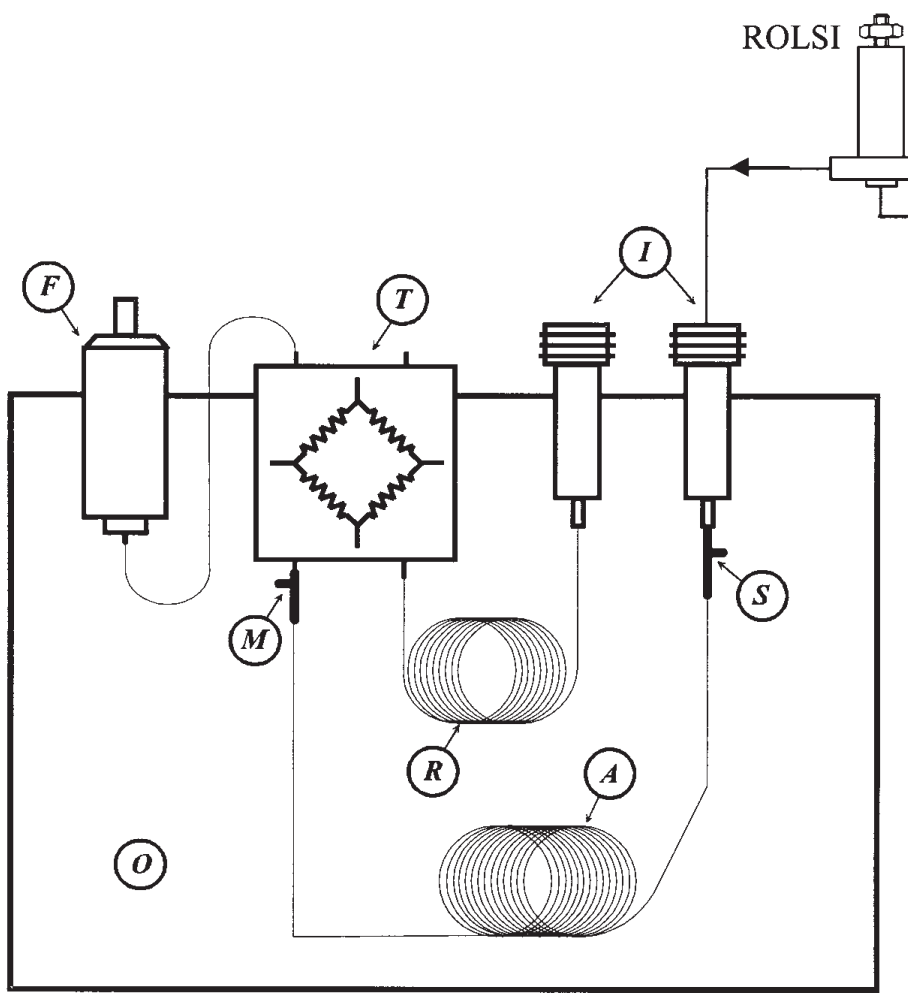

Figure 2. Example of installation of the Sampler-Injector ROLSI on a process line. A micro-sample is withdrawn from the process line and swept by the carrier gas into the injector (I) of a gas chromatograph equipped with a Thermal Conductivity Detector (T) and a Flame Ionisation Detector (F). To decrease the flow rate entering the capillary column (A), a split device (S) is installed in the oven (O) of the chromatograph. A make-up (M) allows restoring a sufficient flow rate entering $T$. $R$ is the reference column. 
running in step) has been found very good; the mean standard deviation is better than $3 \%$ on the withdrawn volume and the mean value remains constant to within $1 \%$.

\section{Operating the Sampler-Injector}

Withdrawn quantities are roughly adjusted using a differential screw (D) acting on the stroke of the bellows (Be) (see figure 1). A fine adjustment is obtained by varying the depressurising time of the counter pressure acting on the bellows contained in the backward part of the sampler through a timer or a PC software. As an example, the sampler was connected to a tubing filled of nitrogen at a pressure of $4 \mathrm{MPa}$ and, for a constant position of the differential screw, the aperture time was varied. Several nitrogen samples were withdrawn from the tubing and sent to the gas chromatograph. After conversion of the chromatographic peak areas to nitrogen volumes (through calibration of the detector using syringes). The evolution of the quantity of nitrogen as

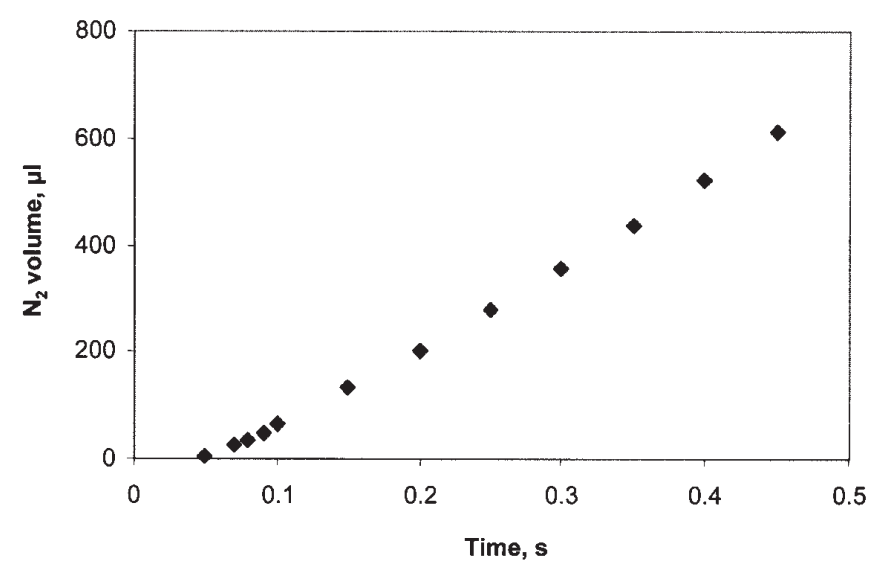

Figure 3. Influence of the aperture time on the size of the samples (for a constant position of the differential screw and a nitrogen pressure $\mathrm{P}=4 \mathrm{MPa}$ ).

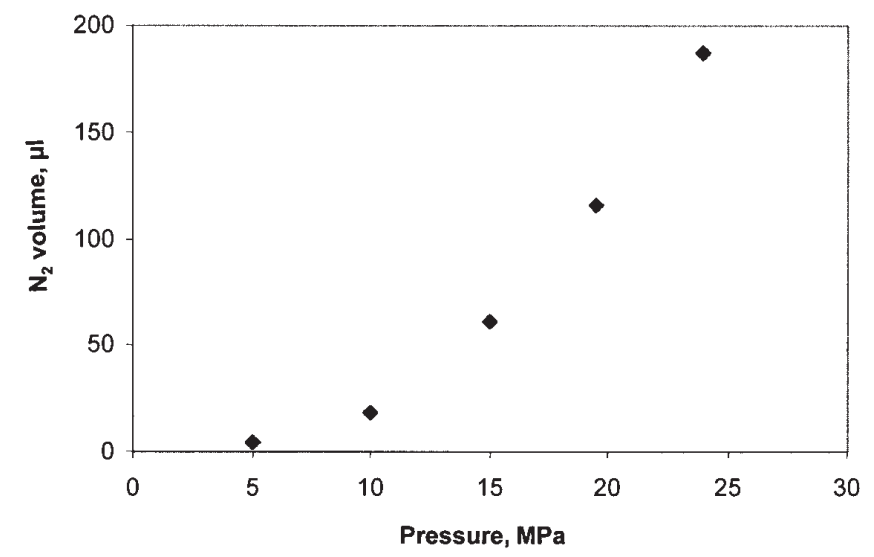

Figure 4. Influence of the pressure on the withdrawn amount (aperture time $=0.4 \mathrm{~s}$ ). a function of the aperture time is reported in figure 3 . It has an almost linear trend. Figure 4 shows that the size of the sample is an exponential-like function of the pressure at which the sample (nitrogen in this example) is withdrawn. In this figure, the differential screw position is different from the one in figure 3, leading to a different stroke of the bellows, then, for the same aperture time and the same sampling pressure as in figure 3 , the withdrawn sample amount is not as in figure 3 .

\section{Results}

Since its conception, the Sampler-Injector has been largely and successfully used inside the laboratory for plenty of experimental studies, mainly the measurement of vapourliquid equilibria, at various conditions of pressures, temperatures and with various fluids. One will find more detailed information about this work in references [12-33]. As often as possible, our work has been compared to available data from the literature (see [12] for instance). Some studies allowed to do some important modifications of the sampler, such as: a) study of vapour-liquid equilibria of mixtures hydrogen-oil up to $673 \mathrm{~K}$ and $40 \mathrm{MPa}$ for British Coal [24]; b) study of the pervaporation phenomenon in the scope of a contract with Électricité de France (withdrawing of samples at $1.5 \mathrm{kPa}$ ) [27]. Recently a large campaign of measurements performed for the Gas Processors Association (GPA) led to the determination of partition coefficients of sulfur compounds at infinite dilution in mixtures of lights hydrocarbons and mixtures of lights hydrocarbons with hydrogen sulfide [30-31]. This study proved the compatibility of the SamplerInjector with analyses by capillary gas chromatography. More recent studies concern the vapour-liquid-liquid equilibria of water-amine-aromatics systems [33].

As an example of quantitative results (analyses by gas chromatography), let us consider the methane hydrogen sulfide mixture at equilibrium in the vapour-liquid state. The mixture is inside an equilibrium cell from which several samples are withdrawn and analysed. The analytical conditions are reported in table I. The calibration of the detector response is done by injecting (using gas chromatographic syringes) known amounts of each component. For a constant position of the differential screw of the sampler and a constant aperture time $\left(\mathrm{T}_{\mathrm{o}}=0.12 \mathrm{~s}\right)$, the chromatographic peak

Table I. Analytical conditions for the analysis, through a DELSI DI 700 gas chromatograph, of the methane-hydrogen sulfide system.

\begin{tabular}{lc}
\hline Detector & TCD (Thermal Conductibility Detector) \\
\hline Column & $\begin{array}{c}\text { Porapak Q }(80 / 100 \mathrm{Mesh}-\text { Silcosteel } \\
1 / 8 " \text { - Length: } 4 \mathrm{~m})\end{array}$ \\
$\begin{array}{l}\text { Oven temperature } \\
\text { Carrier gas (type and } \\
\text { flow rate) }\end{array}$ & $120{ }^{\circ} \mathrm{C}$ \\
\hline
\end{tabular}




\section{Original articles}

areas corresponding to the withdrawn samples at $\mathrm{T}=223 \mathrm{~K}$ and $\mathrm{P}=9.5 \mathrm{MPa}$, are given in table II. The repeatability on the molar fractions of methane is excellent, the standard type deviation being lower than $2.10^{-4}$. In tables III and IV, we report analysis results concerning the same binary system at $\mathrm{T}=274 \mathrm{~K}$ and $\mathrm{P}=8.2 \mathrm{MPa}$, and for samples of different sizes (different $\mathrm{T}_{\mathrm{o}}$ ). Figure 5 shows the Thermal Conductivity Detector response to methane molecules. The calculation of the molar fractions in methane and hydrogen sulfide assuming a linear response (as it appears from the figure), leads to size-dependent data (see table III and figure 6: triangles). This is of course not acceptable. Now, let us adjust the detector response by a second order polynomial. This gives a much better result because, in this case, the molar fractions are totally size-independent (see table IV and figure 6: squares). This example shows how important

Table II. Repeatability of injections (10 samples). (1: methane; 2: hydrogen sulfide; S: chromatographic peak area; $n$ : mole number; $x$ : mole fraction).

\begin{tabular}{lccccc}
\hline Sample & $S_{1}$ & $S_{2}$ & $n_{1}$ & $n_{2}$ & $x_{1}$ \\
\hline 1 & 2342262 & 11697887 & $3.186 \mathrm{E}-06$ & $1.258 \mathrm{E}-05$ & 0.2021 \\
2 & 2303511 & 11485445 & $3.133 \mathrm{E}-06$ & $1.235 \mathrm{E}-05$ & 0.2023 \\
3 & 2288879 & 11416171 & $3.112 \mathrm{E}-06$ & $1.228 \mathrm{E}-05$ & 0.2022 \\
4 & 2328053 & 11609622 & $3.166 \mathrm{E}-06$ & $1.249 \mathrm{E}-05$ & 0.2023 \\
5 & 2255715 & 11263698 & $3.067 \mathrm{E}-06$ & $1.212 \mathrm{E}-05$ & 0.2020 \\
6 & 2271552 & 11342500 & $3.089 \mathrm{E}-06$ & $1.220 \mathrm{E}-05$ & 0.2020 \\
7 & 2243653 & 11173859 & $3.050 \mathrm{E}-06$ & $1.202 \mathrm{E}-05$ & 0.2024 \\
8 & 2220590 & 11086158 & $3.018 \mathrm{E}-06$ & $1.192 \mathrm{E}-05$ & 0.2020 \\
9 & 2400541 & 11980561 & $3.267 \mathrm{E}-06$ & $1.289 \mathrm{E}-05$ & 0.2022 \\
10 & 228938 & 11432828 & $3.113 \mathrm{E}-06$ & $1.230 \mathrm{E}-05$ & 0.2020 \\
\hline
\end{tabular}

Table III. Influence of the withdrawn quantity through a treatment using a wrong calibration. (1: methane; 2: hydrogen sulfide; $\mathrm{S}$ : chromatographic peak area; $n$ : mole number; $x$ : mole fraction).

\begin{tabular}{|c|c|c|c|c|c|c|}
\hline Sample & $T_{0}(\mathrm{sec})$ & $S_{1}$ & $S_{2}$ & $n_{1}$ & $n_{2}$ & $x_{1}$ \\
\hline 1 & 0.58 & 13708576 & 6328037 & $2.005 \mathrm{E}-05$ & $6.806 \mathrm{E}-06$ & 0.7466 \\
\hline 2 & 0.54 & 7207891 & 3182370 & $1.054 \mathrm{E}-05$ & $3.423 \mathrm{E}-06$ & 0.7549 \\
\hline 3 & 0.5 & 3410454 & 1473587 & $4.988 \mathrm{E}-06$ & $1.585 \mathrm{E}-06$ & 0.7589 \\
\hline 4 & 0.55 & 10250237 & 4629626 & $1.499 \mathrm{E}-05$ & $4.980 \mathrm{E}-06$ & 0.7507 \\
\hline 5 & 0.55 & 9640484 & 4348068 & $1.410 \mathrm{E}-05$ & 4.677E-06 & 0.7509 \\
\hline
\end{tabular}

Table IV. Influence of the withdrawn quantity through a treatment using an accurate calibration. (1: methane; 2: hydrogen sulfide; $\mathrm{S}$ : chromatographic peak area; $n$ : mole number; $x$ : mole fraction).

\begin{tabular}{|c|c|c|c|c|c|c|}
\hline Sample & $T_{0}(\mathrm{sec})$ & $S_{1}$ & $S_{2}$ & $n_{l}$ & $n_{2}$ & $x_{1}$ \\
\hline 1 & 0.58 & 13708576 & 6328037 & $1.998 \mathrm{E}-05$ & 6.806E-06 & 0.7459 \\
\hline 2 & 0.54 & 7207891 & 3182370 & $1.010 \mathrm{E}-05$ & $3.423 \mathrm{E}-06$ & 0.7469 \\
\hline 3 & 0.5 & 3410454 & 1473587 & 4.670E-06 & $1.585 \mathrm{E}-06$ & 0.7466 \\
\hline 4 & 0.55 & 10250237 & 4629626 & $1.463 \mathrm{E}-05$ & $4.980 \mathrm{E}-06$ & 0.7461 \\
\hline 5 & 0.55 & 9640484 & 4348068 & $1.371 \mathrm{E}-05$ & $4.677 \mathrm{E}-06$ & 0.7457 \\
\hline
\end{tabular}

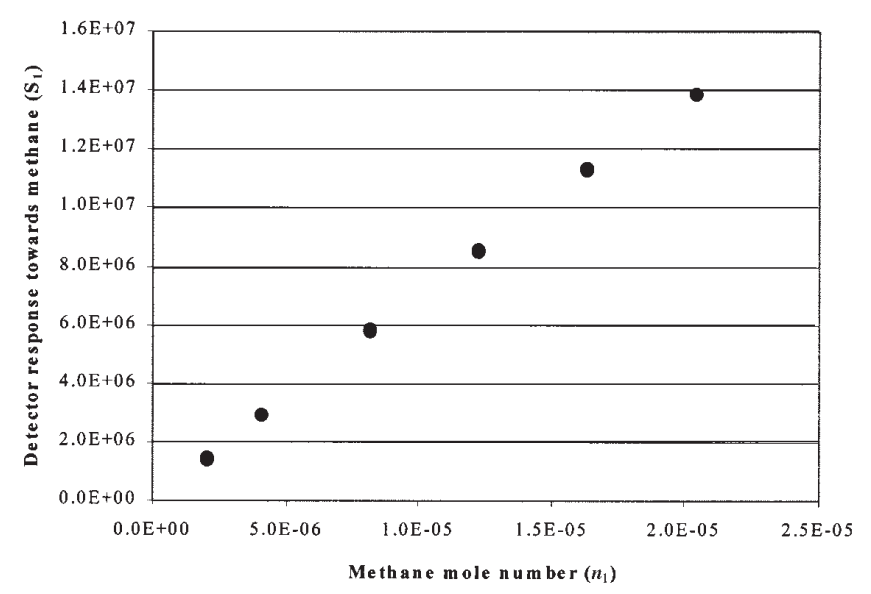

Figure 5. Detector response towards methane.

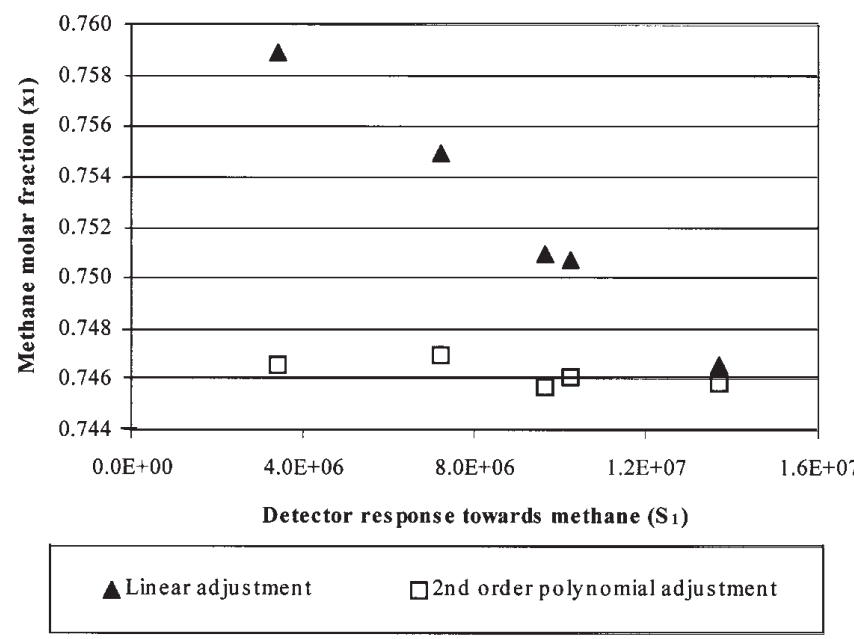

Figure 6. Variation of the methane molar fraction as a function of the methane chromatographic peak areas $S_{1}$ (i.e. as a function of the sample size).

it is to vary samples sizes to check for the reliability of the calibration treatment. This possibility is not easily allowed in traditional sampling systems.

\section{Conclusion}

A lot of Sampler-Injector devices are currently in use, coupled to phase equilibrium measuring cells, in national and international, academic and industrial laboratories. This original system represents a very efficient tool, particularly suited to the study of multiphase equilibria but also to the control of process in chemical and petrochemical plants. Its advantages are the following: measurements up to $100 \mathrm{MPa}$ from 77 to $873 \mathrm{~K}$, continuous adjustment of sample sizes from about one hundredth to some milligrams, no dead 
volumes, independent heating of the sampler, representative samples through in situ withdrawing, analysis of the total samples, corrosion resistance, very easy use, compactness and easy automation.

\section{References}

1. Fraser, M. Proceedings of the Gas Processors Association, 77th Annual Convention, March 16-18, 1998, Dallas, Texas.

2. Peter, S.; Eicke, H.E. Ber Bunsenges Phys. Chem. 1970, 74, 190-194.

3. Pawlikowski, E.M.; Newmann, J.; Prausnitz, J.M. Ind. Eng. Chem. Process Des. Dev. 1982, 21, 764-770.

4. Valuev, K.I.; Kharchenko, A.A.; Lebedev, A.E. Zh. Fiz. Khim. USSR 1972, 46(8), 2135-2137.

5. Jacoby, R.H.; Tracht, J.M. J. of Chromatog. Sci. 1975, 13, 4453.

6. Yarborough, L.; Vogel, J.L. Chem. Eng. Progress Symp. Series 1967, 63(81), 1-9.

7. Ellis, S.R.M.; Walteris, R.M.; Harris, G.J. Chem. Eng. Progress Symp. Series 1968, 88, 16-21.

8. Rodgers, B.L.; Prausnitz, J.M. Ind. Eng. Chem. Fundam. 1970, 9, 174-177.

9. Dorokhov, A.I.; Zakurenov, V.M.; Nozdrev, V.F. Russian J. of Phys. Chem. 1972, 46, 1385-1386.

10. Figuière, P., Hom, J.F.; Laugier, S.; Renon, H.; Richon, D.; Szwarc, H. A. I. Ch. E. J. 1980, 26, 872-875.

11. Laugier, S; Richon, D.; Renon, H. Fuel 1983, 62, 842-844.

12. Laugier, S.; Richon D. Rev. Sci. Instrum. 1986, 57, 469-472.

13. Laugier, S.; Legret, D.; Destève, J.; Richon, D.; Renon, H. G.P.A. Research Report (RR-59), Tulsa, Oklahoma, Project 755.C.80, 1982.

14. Laugier, S.; Alali, P.; Valtz, A.; Chareton, A.; Fontalba, F.; Richon, D.; Renon H. GPA Research Report (RR-75), Tulsa, Oklahoma, Project 755.C.82, 1984.

15. Laugier, S.; Valtz, A.; Chareton, A.; Richon, D.; Renon, H. GPA Research Report (RR-82), Tulsa, Oklahoma, Project 755.C.83 (1984).

16. Laugier, S.; Valtz, A.; Chareton, A.; Richon, D.; Renon, H. GPA Research Report (RR-88), Tulsa, Oklahoma, Project 755.C.84, 1985
17. Chareton, A.; Valtz, A.; Lafeuil, C.; Laugier, S.; Richon, D.; Renon, H. GPA Research Report (RR101), Tulsa, Oklahoma, Project 755.C.85, 1986.

18. Brignole, E.; Chareton, A.; Laugier, S.; Richon, D. J. Chem. Eng. Data 1987, 32, 215-218.

19. Garcia-Sanchez, F; Laugier, S.; Richon, D. J. Chem. Eng. Data 1987, 32, 211-215.

20. Renon, H.; Laugier, S.; Schwartzentruber, J.; Richon, D. Fluid Phase Equilibria 1989, 51, 285-298.

21. Richon, D.; Laugier, S.; Renon, H. J. Chem. Eng. Data 1991, 36, 104-111.

22. Richon, D.; Laugier, S.; Renon, H. J. Chem. Eng. Data 1992, 37, 264-268

23. Laugier, S.; Richon, D.; Renon, H. J. Chem. Eng. Data 1994, 39, 388-391.

24. Lauret, A.; Richon, D.; Renon, H. Int. J. of Energy Research 1994, 18, 267-275.

25. Laugier, S.; Richon, D. J. Chem. Eng. Data 1995, 40(1), 153159.

26. Valtz, A.; Richon, D.; Renon, H. GPA Research Report (RR135), Tulsa, Oklahoma, Project 876, 1995.

27. Bruneau, S.; Viguier, F.; Richon, D. Seventh International Conference on Pervaporation Processes in the Chemical Industry, Published by Bakish Materials Corporation, Englewood, N.J., February 26 to March 2, Reno, Nevada, 1995.

28. Laugier, S.; Richon, D. J. Chem. Eng. Data 1996, 41, 282284.

29. Laugier, S.; Richon, D. J. Chem. Eng. Data 1997, 42, 155159.

30. Guilbot, P.; Valtz, A.; Richon, D. AIDIC Conference Series 1997, 2, 255-262.

31. Guilbot, P.; Valtz, A.; Richon D. Gas Processors Association Research Report RR-162, Tulsa, Oklahoma, Project 876, 1998.

32. Guilbot, P.; Passarello, J.P.; Valtz, A.; Richon, D. Proceedings of the Eighth International Conference on Properties and Phase Equilibria for Product and Process Design, April 26-May 1, 1998, Noordwijkerhout, The Netherlands.

33. Valtz, A.; Guilbot, P.; Richon, D. Gas Processors Association Progress Report, Project 971, Armines, Paris, France, February 1999. 